Article

\title{
A New Macrodiolide and Two New Polycyclic Chromones from the Fungus Penicillium sp. SCSIO041218
}

\author{
Jingxia Huang ${ }^{1,+}{ }^{\dagger}$ Jianglian She ${ }^{2, \dagger}$, Xiliang Yang ${ }^{2, *}$, Juan Liu ${ }^{3}$, Xuefeng Zhou ${ }^{3}$ (I) \\ and Bin Yang ${ }^{3, *(D)}$ \\ 1 Zhongshan Ophthalmic Center, Sun Yat-Sen University, Guangzhou 510060, China; 13694217880@163.com \\ 2 Department of Pharmacy, Hubei Province Key Laboratory of Occupational Hazard Identification \\ and Control, Institute of Infection, Immunology and Tumor Microenvironments, Medical College, \\ Wuhan University of Science of Technology, Wuhan 430081, China; sjlsj10210@163.com \\ 3 CAS Key Laboratory of Tropical Marine Bio-resources and Ecology/Guangdong Key Laboratory of Marine \\ Materia Medica, South China Sea Institute of Oceanology, Chinese Academy of Sciences, \\ Guangzhou 510301, China; liujuan@scsio.ac.cn (J.L.); xfzhou@scsio.ac.cn (X.Z.); \\ * Correspondence: yxlyx1117@163.com (X.Y.); yangbin@scsio.ac.cn (B.Y.) \\ + These two authors contributed equally to this work.
}

Received: 10 April 2019; Accepted: 29 April 2019; Published: 30 April 2019

\begin{abstract}
A new macrodiolide, mangrovlide A (1) and two new polycyclic chromones, penixanthones C (2) and D (3), as well as four other known compounds (4-7), have been isolated from the mangrove sediment derived fungus Penicillium sp. SCSIO041218, cultured in the $0.25 \% \mathrm{NaCl}$ rice substrate. The structures of the new compounds were determined by analysis of the NMR and MS spectroscopic data. Compound 1 possesses a 10-membered macrodiolide unit, while $\mathbf{2}$ and $\mathbf{3}$ are chromones with an unprecedented 6/6/6/5 polycyclic skeleton. Compounds 1-7 were evaluated for their cytotoxicities, while all the compounds displayed weak or no activity.
\end{abstract}

Keywords: marine fungus; Penicillium sp.; penixanthone; macrodiolide; chromone

\section{Introduction}

Fungi are remarkable organisms that have a capacity to produce diverse classes of secondary metabolites with a wide variety of biological activities, such as antimicrobial, anti-HIV, antitumor, anti-inflammatory, and enzymatic inhibitory properties [1-4]. The genus Penicillium, widely found in nature, is among the most studied fungi and represents important drug producers [5,6]. One strain-many compounds (OSMAC) strategy was employed in our investigation on the secondary metabolites of Penicillium sp. SCSIO041218 in various media. Our previous studies on this fungus, cultured in the $0.25 \% \mathrm{NaCl}$ rice substrate, have resulted in discovery of three new diprenylated indole alkaloids, mangrovamides A-C [7]. However, these alkaloids failed to appear in $3 \% \mathrm{NaCl}$ rice substrate, which two new xanthone derivatives, penixanthones $A$ and $B$, were produced [8]. In our continuing search in this productive strain, four new prenylated indole alkaloids and four new chromone derivatives have been isolated in the $1 \% \mathrm{NaCl}$ potato dextrose broth (PDB) medium [9]. The present investigation on the other fractions of the $0.25 \% \mathrm{NaCl}$ rice substrate led to the isolation of a new macrodiolide, mangrovlide A (1) and two new polycyclic chromones, penixanthones C (2) and D (3), as well as four other known compounds 4-hydroxy-6-methoxy-5-methylphthalid (4), methyl 2-(5-hydroxy-2,3,4-trimethylphenyl) propionate (5), dehydromevalonic lactone (6), $(R)$-mevalonolactone (7) (Figure 1). In this paper, we report the isolation, structure elucidation, and the bioactivities of these compounds. 

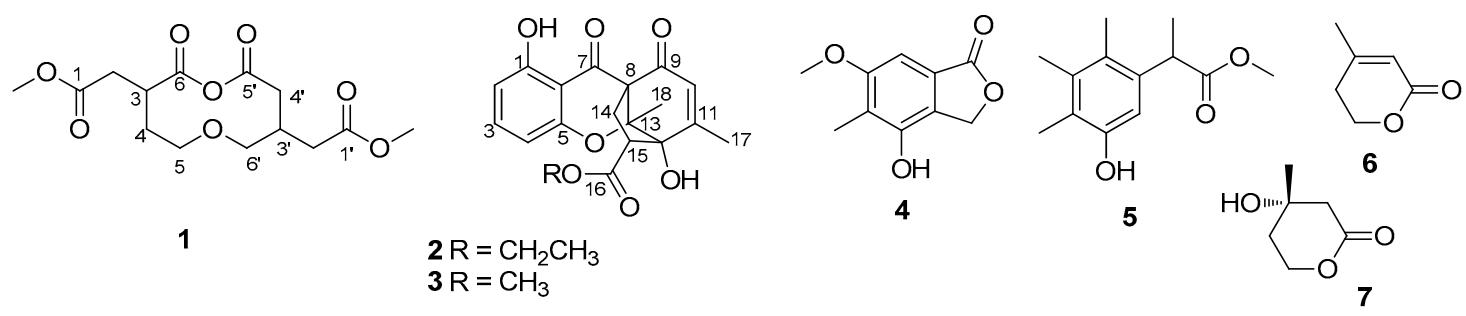

Figure 1. Structures of compounds 1-7.

\section{Results}

Compound 1 was obtained as a colorless oil. Its molecular formula was assigned as $\mathrm{C}_{14} \mathrm{H}_{20} \mathrm{O}_{8}$ based on the positive HR-ESI-MS at $m / z 339.1059[\mathrm{M}+\mathrm{Na}]^{+}$, accounting for five degrees of unsaturation. Analysis of ${ }^{13} \mathrm{C} \mathrm{NMR}$ (Table 1, Supplementary Materials) and distortionless enhancement by polarization transfer (DEPTs) spectra revealed the presence of four carbonyl carbons, two methines, six methylenes (including two O-methylenes), and two O-methyl. Comprehensive analysis of the 2D NMR spectra of 1, especially ${ }^{1} \mathrm{H}-{ }^{1} \mathrm{H}$ homonuclear correlated spectroscopy (COSY) and heteronuclear multiple bond correlation (HMBC), allowed the establishment of the structure. Two structural fragments $\left.\left[C-2 / C-3 / C-4 / C-5, C-2^{\prime} / C-3^{\prime}\left(C-6^{\prime}\right) / C-4^{\prime}\right)\right]$ were established by the correlations observed in the ${ }^{1} \mathrm{H}-{ }^{1} \mathrm{H}$ COSY spectrum (Figure 2). This structure was also supported by the correlations of $\mathrm{H}-2$ to C-1, C-3, and C-6, H-5 to C-4, and C-3, H-2' to C-1', $\mathrm{H}-4^{\prime}$ to $\mathrm{C}-2^{\prime}, \mathrm{C}-3^{\prime}, \mathrm{C}-5^{\prime}$, and $\mathrm{C}-6^{\prime}, \mathrm{H}-6^{\prime}$ to $\mathrm{C}-2^{\prime}$, and $\mathrm{C}-3^{\prime}$ in the HMBC experiment. The four carbonyl carbons accounted for four out of five degrees of unsaturation, and the remaining one degree of unsaturation required the presence of one additional ring in $\mathbf{1}$. Taking the molecular formula into account, the planar structure of 1, consisting of 10-membered macrodiolide unit, could then be constructed as shown in Figure 1. The configurations of $\mathbf{1}$ were not determined, because extensive efforts were unsuccessful, including produce suitable crystals for X-ray diffraction. Thus, the planar structure was established and assigned the trivial name mangrovlide A (1).

Table 1. ${ }^{1} \mathrm{H}$ and ${ }^{13} \mathrm{C}$ NMR data for $1\left(500 / 125 \mathrm{MHz}\right.$, in $\left.\mathrm{CD}_{3} \mathrm{OD}\right)$.

\begin{tabular}{|c|c|c|}
\hline Position & $\delta_{\mathrm{H}}$, mult, $J$ in $\mathrm{Hz}$ & $\delta_{\mathrm{C}}$ \\
\hline 1 & & 172.0 \\
\hline \multirow[t]{2}{*}{2} & $2.83 \mathrm{dd}(12.5,3.5)$ & 33.4 \\
\hline & $2.67 \mathrm{dd}(12.5,5.5)$ & \\
\hline 3 & $3.05 \mathrm{~m}$ & 35.8 \\
\hline \multirow[t]{2}{*}{4} & $2.52 \mathrm{~m}$ & 27.8 \\
\hline & $2.14 \mathrm{~m}$ & \\
\hline \multirow[t]{2}{*}{5} & $4.43 \mathrm{td}(6.5,1.5)$ & 66.8 \\
\hline & $\begin{array}{c}4.29 \text { ddd }(9.0,5.0 \text {, } \\
5.0)\end{array}$ & \\
\hline 6 & & 179.6 \\
\hline $\mathrm{OMe}$ & $3.71 \mathrm{~s}$ & 50.8 \\
\hline $1^{\prime}$ & & 172.2 \\
\hline $2^{\prime}$ & $2.59 \mathrm{dd}(5.0,1.5)$ & 36.1 \\
\hline $3^{\prime}$ & $2.99 \mathrm{dt}(11.5,5.0)$ & 31.8 \\
\hline \multirow[t]{2}{*}{$4^{\prime}$} & $2.75 \mathrm{dd}(12.5,6.5)$ & 33.3 \\
\hline & $2.36 \mathrm{dd}(12.5,5.5)$ & \\
\hline $5^{\prime}$ & & 178.1 \\
\hline \multirow[t]{2}{*}{$6^{\prime}$} & $4.55 \mathrm{dd}(6.5,5.5)$ & 72.8 \\
\hline & $4.06 \mathrm{dd}(6.5,5.0)$ & \\
\hline $\mathrm{OMe}$ & $3.70 \mathrm{~s}$ & 50.9 \\
\hline
\end{tabular}

Compound 2 was obtained as colorless syrup. Its molecular formula was established as $\mathrm{C}_{20} \mathrm{H}_{20} \mathrm{O}_{7}$ on the basis of the positive HRESIMS at $m / z 373.1276[\mathrm{M}+\mathrm{H}]^{+}, 395.1092[\mathrm{M}+\mathrm{Na}]^{+}$, accounting for eleven degrees of unsaturation. The ${ }^{1} \mathrm{H}$ NMR spectrum (Table 2, Supplementary Materials) showed 
three aromatic and one olefinic protons $\left[\delta_{\mathrm{H}} 7.39(1 \mathrm{H}, \mathrm{t}, J=8.5 \mathrm{~Hz}, \mathrm{H}-3), 6.59(1 \mathrm{H}, \mathrm{d}, J=8.5 \mathrm{~Hz}, \mathrm{H}-4)\right.$, $6.44(1 \mathrm{H}, \mathrm{d}, J=8.5 \mathrm{~Hz}, \mathrm{H}-2), 6.03(1 \mathrm{H}, \mathrm{s}, \mathrm{H}-10)]$, two methyl singlets [ $\delta_{\mathrm{H}} 2.02(3 \mathrm{H}, \mathrm{s}, \mathrm{H}-17), 1.38(3 \mathrm{H}, \mathrm{s}$, $\mathrm{H}-18)]$, one methyl triplet $\left[\delta_{\mathrm{H}} 1.29(3 \mathrm{H}, \mathrm{t}, J=7.5 \mathrm{~Hz}, \mathrm{H}-20)\right]$, and one $O$-methylene $\left[\delta_{\mathrm{H}} 4.26(2 \mathrm{H}, \mathrm{m}\right.$, $\mathrm{H}-19)]$. The ${ }^{13} \mathrm{C}$ NMR, DEPT, and heteronculear single quantum coherence (HSQC) data revealed the presence of three methyls $\left(\delta_{C} 13.4,14.2,19.2\right)$, two sp ${ }^{3}$ methylenes $\left(\delta_{C} 32.0,61.7\right)$, one sp ${ }^{3}$ methine $\left(\delta_{C} 52.5\right)$, three $\mathrm{sp}^{3}$ quaternary carbons $\left(\delta_{C} 61.2,86.1,92.4\right)$, four $\mathrm{sp}^{2}$ methines $\left(\delta_{C} 107.9,111.3,127.0\right.$, $138.5)$, four $\mathrm{sp}^{2}$ quaternary carbon $\left(\delta_{\mathrm{C}} 105.8,156.9,160.1,163.4\right)$, one carbonyl carbon $\left(\delta_{C} 170.8\right)$ and two ketones $\left(\delta_{C} 191.0,193.6\right)$. Since eight of the eleven degrees of unsaturation were attributed to one aromatic moiety, one trisubstituted double bond, one carbonyl and two ketones, 2 was assumed to contain three other rings.
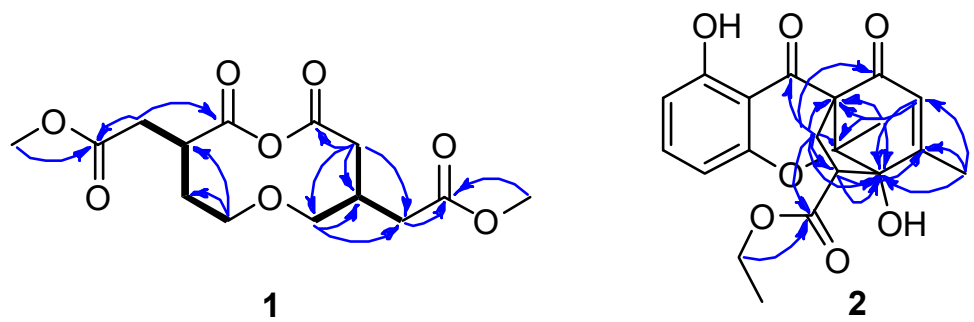

Figure 2. Key HMBC and ${ }^{1} \mathrm{H}-{ }^{1} \mathrm{H}$ COSY correlations of compounds $\mathbf{1}$ and $\mathbf{2}$.

Table 2. ${ }^{1} \mathrm{H}$ and ${ }^{13} \mathrm{C}$ NMR data for 2 and $3\left(500 / 125 \mathrm{MHz}\right.$, in $\left.\mathrm{CDCl}_{3}\right)$.

\begin{tabular}{|c|c|c|c|c|}
\hline \multirow{2}{*}{ Position } & \multicolumn{2}{|l|}{2} & \multicolumn{2}{|l|}{3} \\
\hline & $\delta_{\mathrm{H}}$, mult, $J$ in $\mathrm{Hz}$ & $\delta_{\mathrm{C}}$ & $\delta_{\mathrm{H}}$, mult, $J$ in $\mathrm{Hz}$ & $\delta_{\mathrm{C}}$ \\
\hline 1 & & 156.9 & & 156.9 \\
\hline 2 & $6.44 \mathrm{~d}(8.5)$ & 107.9 & $6.45 \mathrm{~d}(8.0)$ & 107.9 \\
\hline 3 & $7.39 \mathrm{t}(8.5)$ & 138.5 & $7.40 \mathrm{t}(8.0)$ & 138.5 \\
\hline 4 & $6.59 \mathrm{~d}(8.5)$ & 111.3 & $6.60 \mathrm{~d}(8.0)$ & 111.4 \\
\hline 5 & & 163.4 & & 163.4 \\
\hline 6 & & 105.8 & & 106.0 \\
\hline 7 & & 191.0 & & 191.1 \\
\hline 8 & & 61.2 & & 61.2 \\
\hline 9 & & 193.6 & & 193.5 \\
\hline 10 & $6.03 \mathrm{~s}$ & 127.0 & $6.02 \mathrm{~s}$ & 127.1 \\
\hline 11 & & 160.1 & & 160.0 \\
\hline 12 & & 86.1 & & 86.2 \\
\hline 13 & & 92.4 & & 92.4 \\
\hline $14 \alpha$ & $2.59 \mathrm{dd}(7.0,15.0)$ & 32.0 & $2.60 \mathrm{dd}(7.0,15.0)$ & 32.0 \\
\hline $14 \beta$ & $2.46 \mathrm{dd}(10.0,15.0)$ & & $2.46 \mathrm{dd}(10.0,14.5)$ & \\
\hline 15 & $3.73 \mathrm{~m}$ & 52.5 & $3.74 \mathrm{t}(8.0)$ & 52.5 \\
\hline 16 & & 170.8 & & 171.2 \\
\hline 17 & $2.02 \mathrm{~s}$ & 19.2 & $2.00 \mathrm{~s}$ & 19.0 \\
\hline 18 & $1.38 \mathrm{~s}$ & 13.4 & $1.37 \mathrm{~s}$ & 13.4 \\
\hline 19 & $4.26 \mathrm{~m}$ & 61.7 & $3.76 \mathrm{~s}$ & 52.5 \\
\hline 20 & $1.29 \mathrm{t}(7.5)$ & 14.2 & & \\
\hline
\end{tabular}

Through careful analysis of the 1D and 2D NMR data, 2 was found to be similar to mangrovamide $\mathrm{J}$ [9], which was isolated from the same fungus with $1 \% \mathrm{NaCl}$ PDB substrate. HMBC correlations from H-2 to C-1, and C-6; H-3 to C-1, and C-5; and H-4 to C-5 led to the connectivity of the subunits to form a trisubstituted aromatic moiety. Also, the HMBC correlations from $\mathrm{H}-10$ to $\mathrm{C}-12, \mathrm{C}-13$ and $\mathrm{C}-17 ; \mathrm{H}_{3}-17$ to $\mathrm{C}-10, \mathrm{C}-11$, and $\mathrm{C}-12$; and $\mathrm{H}_{3}-18$ to $\mathrm{C}-8, \mathrm{C}-12$, and $\mathrm{C}-13$, constructed the typical chromone three rings in 2 . The remaining signals in $\mathbf{2}$ were completely different from other chromone derivatives. Since the preceding data accounted for 11 degrees of unsaturation, the presence of an additional ring was required to satisfy the molecular formula of 2. Key HMBC correlations from H-14 to C-7, C-8, C-9, C-12, 
C-13, C-15 and C-16; H-15 to C-11, C-12, C-14, and C-16 revealed the connectivity between C-8 and $\mathrm{C}-13$. Furthermore, one ethyl group positioned at $\mathrm{C}-19$ was confirmed from the HMBC correlations from $\delta_{\mathrm{H}} 4.26(\mathrm{H}-19)$ to the ester carbonyl carbon resonating at $\delta_{\mathrm{C}} 170.8$. Thus, the gross structure of penixanthone $\mathrm{C}$ was assigned as $\mathbf{2}$. In comparison to the well-established chromone derivatives, 2 possesses an unprecedented signature $C_{2}$ bridge and corresponding fused five member ring [10,11]. In the nuclear overhauser effect spectroscopy (NOESY) spectrum (Figure 3), correlations of $\mathrm{H}_{3}-17$ to $\mathrm{H}-10$ and $\mathrm{H}-14 \beta$ to $\mathrm{H}-15$ were found. Due to the baseline ECD curves and barely measurable specific rotation values, compound 2 was presumed to be racemic.

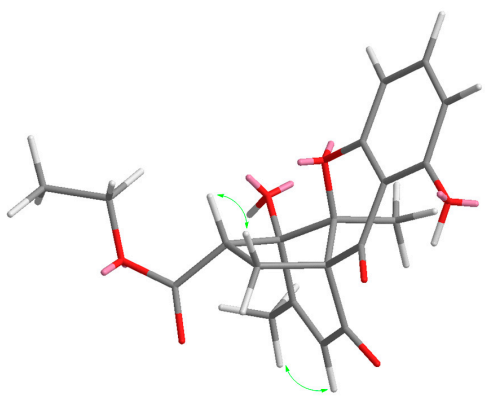

Figure 3. NOESY correlations of compound 2.

Compound 3 was obtained as colorless syrup. Its molecular formula was established as $\mathrm{C}_{19} \mathrm{H}_{18} \mathrm{O}_{7}$ on the basis of the positive HRESIMS at $m / z 359.1127[\mathrm{M}+\mathrm{H}]^{+}, 381.0941[\mathrm{M}+\mathrm{Na}]^{+}$, accounting for eleven degrees of unsaturation. The ${ }^{1} \mathrm{H}$ and ${ }^{13} \mathrm{C}$ NMR spectra (Table 2, Supplementary Materials) of 3 were similar to those of $\mathbf{2}$, with the exception that the ethyl group of the latter was replaced by a methyl singlet at $\delta 3.76$. So, the structure of 3 was established and assigned the trivial name penixanthone $\mathrm{D}$ (3), as shown in Figure 1.

The identities of compounds 4-7 were established by comparison of their spectral data with those of the known compounds reported. They are 4-hydroxy-6-methoxy-5-methylphthalid (4) [12-14], methyl 2-(5-hydroxy-2,3,4-trimethylphenyl) propionate (5) [15], dehydromevalonic lactone (6) [16], (R)-mevalonolactone (7) $[17,18]$.

Compounds 1-7 were tested for their in vitro cytotoxicities against 10 human tumor cell lines (H1975, U937, K562, BGC823, MOLT-4, MCF-7, A549, Hela, HL60 and Huh-7). Only 2 and 3 showed weak activities against K562 (2: $55.2 \mu \mathrm{M}, 3: 56.5 \mu \mathrm{M})$, MCF-7 (2: $61.1 \mu \mathrm{M}, 3: 58.6 \mu \mathrm{M})$, Huh-7 (2: $67.5 \mu \mathrm{M}, 3: 64.2 \mu \mathrm{M})$ cell lines, with $\mathrm{IC}_{50}$ values of $55.2-67.5 \mu \mathrm{M}$. Trichostatin A was used as the positive control with $\mathrm{IC}_{50}$ values of $0.027 \mu \mathrm{M}-0.162 \mu \mathrm{M}$.

\section{Experimental Section}

\subsection{General Experimental Procedures}

The NMR spectra were recorded on a Bruker AC 500 NMR spectrometer (BrukerBioSpin, Fällanden, Switzerland) with TMS as an internal standard. ESI-MS data were measured on a BrukeramaZon SL spectrometer (Bruker, Fällanden, Switzerland). HR-ESI-MS data were measured on a Bruker micro TOF-QII mass spectrometer (Bruker, Fällanden, Switzerland). UV spectrum was measured by using a Shimadzu UV-2600 PC spectrometer (Shimadzu, Beijing, China). IR spectrum was recorded on an IR-Affinity-1 spectrometer (Shimadzu, Beijing, China). CD spectra were measured with Chirascan circular dichroism spectrometer (Applied Photophysics Ltd., Leatherhead, UK). Optical rotation values were measured with an Anton Paar MCP500 polarimeter (Anton Paar, Graz, Austria). YMC gel (ODS-A, $12 \mathrm{~nm}$, S-50 mm, YMC, Kyoto, Japan) was used for column chromatography. Phenomenex column (Lux Cellulose-2 column, $4.6 \mathrm{~mm} \times 25 \mathrm{~mm}$, Phenomenex, Torrance, CA, USA) was used for chiral analysis HPLC chromatography. The $\mathrm{SiO}_{2} \mathrm{GF}_{254}$ used for TLC was supplied by the Qingdao Marine Chemical Factory, Qingdao, China. Sephadex LH-20 gel (GE Healthcare, Uppsala, Sweden) 
was used. HPLC was carried out on Hitachi L-2400 with YMC ODS column (Hitachi, Tokyo, Japan). Spots were detected on TLC under UV light or by heating after spraying with $5 \% \mathrm{H}_{2} \mathrm{SO}_{4}$ in EtOH $(v / v)$.

\subsection{Fungal Material}

The culture of Penicillium sp. SCSIO041218 (Original Number: SYFz-1) was isolated from a mangrove sediment sample collected in Sanya $\left(18^{\circ} 13^{\prime} 50.2^{\prime \prime} \mathrm{N}, 109^{\circ} 37^{\prime} 15.8^{\prime \prime} \mathrm{E}\right)$ in August 2010. The strain (accession NO. JN713906.1) was identified as Penicillium sp. based on a molecular biological protocol calling for DNA amplification and ITS region sequence comparison with the GenBank database and shared a similarity of $100 \%$ with Penicillium funiculosum. The strain was deposited in the RNAM Center, South China Sea Institute of Oceanology, Chinese Academy of Sciences, Guangzhou, China.

\subsection{Fermentation and Purification}

Strain stored on PDA slants at $4{ }^{\circ} \mathrm{C}$ was cultured on PDA agar plates and incubated for 7 days. Seed medium (potato $200 \mathrm{~g}$, dextrose $20 \mathrm{~g}, \mathrm{NaCl} 2.5 \mathrm{~g}$, distilled water $1000 \mathrm{~mL}$ ) in 50-mL Erlenmeyer flasks was inoculated with strain F00120 and incubated at $25^{\circ} \mathrm{C}$ for $48 \mathrm{~h}$ on a rotating shaker $(180 \mathrm{rpm})$. Production medium of solid rice in $1000 \mathrm{~mL}$ flasks (rice $200 \mathrm{~g}, \mathrm{NaCl} 0.5 \mathrm{~g}$, distilled water $200 \mathrm{~mL}$ ) was inoculated with $10 \mathrm{~mL}$ seed solution. Flasks were incubated at $25^{\circ} \mathrm{C}$ under static stations and daylight. After 50 days, cultures from 10 flasks were harvested for the isolation of substances.

The total $2 \mathrm{~kg}$ of rice culture was crushed and extracted with acetone three times. The acetone extract was evaporated under reduced pressure to afford an aqueous solution, and then the aqueous solution was extracted with EtOAc to yield $29 \mathrm{~g}$ of a crude gum. The EtOAc portion was subsequently separated by $\mathrm{Si}$ gel column chromatography using $\mathrm{CHCl}_{3}-\mathrm{MeOH}$ gradient elution to give seventeen fractions (Frs. A Q). Fr. $D$ was purified by semipreparative RP HPLC $\left(70 \% \mathrm{MeOH}\right.$ in $\left.\mathrm{H}_{2} \mathrm{O}\right)$ at a flow rate of $3 \mathrm{~mL} / \mathrm{min}$ to afford $2(3.3 \mathrm{mg}), 3(2.4 \mathrm{mg})$. Fr. $H$ was further separated by semipreparative reversed-phase $\mathrm{HPLC}\left(75 \% \mathrm{MeOH}\right.$ in $\left.\mathrm{H}_{2} \mathrm{O}\right)$ at a flow rate of $3 \mathrm{~mL} / \mathrm{min}$ to afford $6(4.6 \mathrm{mg})$, and $7(3.1 \mathrm{mg})$. Fr. $J$ was further purified by CC over ODS with MPLC, using gradient elution from $20 \% \mathrm{MeOH}$ to $100 \%$ at a flow rate of $15 \mathrm{~mL} / \mathrm{min}$, to yield 12 portions (Fr. J-1 Fr. J-12). Fr. J-4 was further separated by semipreparative reversed-phase HPLC ( $55 \% \mathrm{MeOH}$ in $\mathrm{H}_{2} \mathrm{O}$ ) at a flow rate of $3 \mathrm{~mL} / \mathrm{min}$ to afford 1 (5.6 mg). Fr. K was further purified by CC over ODS with MPLC, using gradient elution from $20 \%$ $\mathrm{MeOH}$ to $100 \%$ at a flow rate of $15 \mathrm{~mL} / \mathrm{min}$, to yield 17 portions (Fr. K-1 Fr. K-17). Fr. J-5 was further separated by semipreparative reversed-phase HPLC $\left(45 \% \mathrm{MeOH}\right.$ in $\left.\mathrm{H}_{2} \mathrm{O}\right)$ at a flow rate of $3 \mathrm{~mL} / \mathrm{min}$ to afford $5(3.0 \mathrm{mg})$. Fr. $M$ was further separated by semipreparative reversed-phase HPLC ( $45 \% \mathrm{MeOH}$ in $\left.\mathrm{H}_{2} \mathrm{O}\right)$ at a flow rate of $3 \mathrm{~mL} / \mathrm{min}$ to afford $4(4.0 \mathrm{mg})$.

Mangrovlide A (1): colorless oil; $[\alpha]_{\mathrm{D}}^{25}=-3.1(0.1, c, \mathrm{MeOH}) ; \mathrm{UV}(\mathrm{MeOH}) \lambda_{\max }(\log \varepsilon): 204(0.74) \mathrm{nm}$; IR (film) $v_{\max }: 3365,1645,1016 \mathrm{~cm}^{-1} ;{ }^{1} \mathrm{H}$ and ${ }^{13} \mathrm{C}$ NMR in Table 1 ; HR-ESI-MS $\mathrm{m} / z 339.1059$ [M + Na] ${ }^{+}$ (Calcd for $\mathrm{C}_{14} \mathrm{H}_{20} \mathrm{NaO}_{8} 339.1050$ ).

Penixanthone C (2): colorless syrup; $[\alpha]_{\mathrm{D}}^{25}=-10.4(0.1, c, \mathrm{MeOH}) ; \mathrm{UV}(\mathrm{MeOH}) \lambda_{\max }(\log \varepsilon): 207$ (1.63), 274 (0.61), 353 (0.19) nm; IR (film) $v_{\max }: 3481,1622,1205,1010 \mathrm{~cm}^{-1} ;{ }^{1} \mathrm{H}$ and ${ }^{13} \mathrm{C}$ NMR in Table 2; HR-ESI-MS m/z 373.1276 [M + H] ${ }^{+}$(Calcd for $\mathrm{C}_{20} \mathrm{H}_{21} \mathrm{O}_{7}$ 373.1282), $m / z 395.1092[\mathrm{M}+\mathrm{Na}]^{+}$(Calcd for $\mathrm{C}_{20} \mathrm{H}_{20} \mathrm{NaO}_{7}$ 395.1088).

Penixanthone D (3): colorless syrup; $[\alpha]_{\mathrm{D}}^{25}=-6.8(0.12, c, \mathrm{MeOH}) ; \mathrm{UV}(\mathrm{MeOH}) \lambda_{\max }(\log \varepsilon): 207(1.63)$, 274 (0.61), 353 (0.19) nm; IR (film) $v_{\max }: 3361,1624,1014 \mathrm{~cm}^{-1} ;{ }^{1} \mathrm{H}$ and ${ }^{13} \mathrm{C}$ NMR in Table 2; HR-ESI-MS $m / z 359.1127[\mathrm{M}+\mathrm{H}]^{+}\left(\right.$Calcd for $\left.\mathrm{C}_{19} \mathrm{H}_{19} \mathrm{O}_{7} 359.1125\right), m / z 381.0941[\mathrm{M}+\mathrm{Na}]^{+}\left(\right.$Calcd for $\mathrm{C}_{19} \mathrm{H}_{18} \mathrm{NaO}_{7}$ 381.0945).

\section{Conclusions}

The investigation of bioactive natural products from the fungus Penicillium sp. SCSIO041218, cultured in the $0.25 \% \mathrm{NaCl}$ rice substrate, have resulted in discovery of a new macrodiolide, mangrovlide 
A (1) and two new polycyclic chromones, penixanthones L (2) and M (3), along with four other known compounds 4-hydroxy-6-methoxy-5-methylphthalid (4), methyl 2-(5-hydroxy-2,3,4-trimethylphenyl) propionate (5), dehydromevalonic lactone (6), and (R)-mevalonolactone (7). They feature a unique natural product framework. The unique structure and chemical properties of 1-3 are attractive for chemists and biologists.

Supplementary Materials: The following are available online, Biological assays, Figure S1. ${ }^{1} \mathrm{H}$ NMR spectra of 1 in $\mathrm{CD}_{3} \mathrm{OD}$, Figure S2. ${ }^{13} \mathrm{C}$ NMR spectra of $\mathbf{1}$ in $\mathrm{CD}_{3} \mathrm{OD}$, Figure S3. HSQC spectra of $\mathbf{1}$, Figure S4. HMBC spectra of 1, Figure S5. ${ }^{1} \mathrm{H}-{ }^{1} \mathrm{H}$ COSY spectrum of 1, Figure S6. HRESIMS spectrum of 1, Figure S7. ${ }^{1} \mathrm{H}$ NMR spectra of 2 in $\mathrm{CD}_{3} \mathrm{OD}$, Figure S8. ${ }^{13} \mathrm{C}$ NMR spectra of 2 in $\mathrm{CD}_{3} \mathrm{OD}$, Figure S9. HSQC spectra of 2, Figure S10. HMBC spectra of 2, Figure S11. HRESIMS spectrum of 2, Figure S12. Compare ${ }^{1} \mathrm{H}$ NMR spectra between 2 and 3, Figure S13. Compare ${ }^{13} \mathrm{C}$ NMR spectra between 2 and 3, Figure S14. CD data of 1, Figure S15. CD data of 2 and 3.

Author Contributions: J.H. and J.S. fractionated the extract, isolated the compounds, and performed the bioassays. X.Z. and J.L. analyzed the data. X.Y. and B.Y. elucidated the structures, and wrote the paper.

Funding: This study was supported by grants from the National Natural Science Foundation of China (21772210, 41776169), Guangzhou Science and Technology Project (201804010462), the Natural Science Foundation of Guangdong Province (2018A0303130219), the Scientific Research Projects of Hubei education department for Young Scholars (Q20171109), Special Funds for Promoting Economic Development (Marine Economic Development) of Guangdong Province (GDME-2018C010), National Major Scientific and Technological Special Project for Significant New Drugs Development (2018ZX09735001-002-003).

Acknowledgments: We are grateful to Z. Xiao, A. Sun, C. Li, and Y. Zhang in the analytical facilities at SCSIO for recording spectroscopic data.

Conflicts of Interest: The authors declare no conflict of interest.

\section{References}

1. Carroll, A.R.; Copp, B.R.; Davis, R.A.; Keyzers, R.A.; Prinsep, M.R. Marine natural products. Nat. Prod. Rep. 2019, 36, 122-173. [CrossRef] [PubMed]

2. Bugni, T.S.; Ireland, C.M. Marine-derived fungi: A chemically and biologically diverse group of microorganisms. Nat. Prod. Rep. 2004, 21, 143-163. [CrossRef] [PubMed]

3. Bhatnagar, I.; Kim, S.-K. Immense Essence of Excellence: Marine Microbial Bioactive Compounds. Mar. Drugs 2010, 8, 2673-2701. [CrossRef]

4. Wang, Y.; Xue, Y.; Liu, C. A Brief Review of Bioactive Metabolites Derived from Deep-Sea Fungi. Mar. Drugs 2015, 13, 4594-4616. [CrossRef]

5. Geisen, R.; Schmidt-Heydt, M.; Touhami, N.; Himmelsbach, A. New aspects of ochratoxin A and citrinin biosynthesis in Penicillium. Curr. Opin. Food Sci. 2018, 23, 23-31. [CrossRef]

6. Bladt, T.T.; Frisvad, J.C.; Knudsen, P.B.; Larsen, T.O. Anticancer and Antifungal Compounds from Aspergillus, Penicillium and Other Filamentous Fungi. Molecules 2013, 18, 11338-11376. [CrossRef] [PubMed]

7. Yang, B.; Dong, J.; Lin, X.; Zhou, X.; Zhang, Y.; Liu, Y. New prenylated indole alkaloids from fungus Penicillium sp. derived of mangrove soil sample. Tetrahedron 2014, 70, 3859-3863. [CrossRef]

8. Tao, H.M.; Wei, X.Y.; Lin, X.P.; Zhou, X.F.; Dong, J.D.; Yang, B. Penixanthones A and B, two new xanthone derivatives from fungus Penicillium sp. SYFz-1 derived of mangrove soil sample. Nat. Prod. Res. 2017, 31, 2218-2222. [CrossRef] [PubMed]

9. Yang, B.; Tao, H.; Lin, X.; Wang, J.; Liao, S.; Dong, J.; Zhou, X.; Liu, Y. Prenylated indole alkaloids and chromone derivatives from the fungus Penicillium sp. SCSIO041218. Tetrahedron 2018, 74, 77-82. [CrossRef]

10. Li, J.; Zhou, S.; Chen, P.; Dong, L.; Liu, T.; Chen, Y. Asymmetric Diels-Alder reaction of $\beta$, $\beta$-disubstituted enals and chromone-fused dienes: Construction of collections with high molecular complexity and skeletal diversity. Chem. Sci. 2012, 3, 1879-1882. [CrossRef]

11. Ai, W.; Wei, X.; Lin, X.; Sheng, L.; Wang, Z.; Tu, Z.; Yang, X.; Zhou, X.; Li, J.; Liu, Y. Guignardins A-F, spirodioxynaphthalenes from the endophytic fungus Guignardia sp. KcF8 as a new class of PTP1B and SIRT1 inhibitors. Tetrahedron 2014, 70, 5806-5814. [CrossRef]

12. Proksa, B.; Uhrin, D.; Fuska, J.; Michalkova, E. (-)-Mitorubrinol and Phthaldehydic Acids, New Metabolites of Penicillium vermiculatum DANG. Collect. Czech. Chem. C 1992, 57, 408-414. [CrossRef] 
13. Ayer, W.A.; Racok, J.S. The metabolites of Talaromyces flavus. Part 2. Biological activity and biosynthetic studies. Can. J. Chem. 1990, 68, 2095-2101. [CrossRef]

14. Ayer, W.A.; Racok, J.S. The metabolites of Talaromycesflavus: Part 1. Metabolites of the organic extracts. Can. J. Chem. 1990, 68, 2085-2094. [CrossRef]

15. Cox, R.E.; Holker, J.S.E. The biosynthesis of fungal metabolites. Part IX. Sclerin: feedings with $\left[1,2-{ }^{13} \mathrm{C}\right]$ acetate and [methyl- ${ }^{13} \mathrm{C}$ ]methionine. J. Chem. Soc. Perkin Trans. 1 1976, 19, 2077-2079. [CrossRef]

16. Krings, U.; Zelena, K.; Wu, S.M.; Berger, R.G. Thin-layer high-vacuum distillation to isolate volatile flavour compounds of cocoa powder. Eur. Food Res. Technol. 2006, 223, 675-681. [CrossRef]

17. Pichat, L.; Blagoev, B.; Hardouin, J.C. Synithesis of de-mevalonic acid (5-14C) lactone. Bull. Soc. Chim. Fr. 1968, 11, 4489-4490.

18. Xu, Z.; Wu, X.; Li, G.; Feng, Z.; Xu, J. Pestalotiopisorin B, a new isocoumarin derivative from the mangrove endophytic fungus Pestalotiopsis sp. HHL101. Nat. Prod. Res. 2019, 1-6. [CrossRef]

Sample Availability: Samples of the compounds 1-7 are available from the authors.

(C) 2019 by the authors. Licensee MDPI, Basel, Switzerland. This article is an open access article distributed under the terms and conditions of the Creative Commons Attribution (CC BY) license (http://creativecommons.org/licenses/by/4.0/). 